\title{
LITTLE-KNOWN SCIENTIFIC CONTRIBUTIONS OF J-M CHARCOT
}

Helio A. G. Teive*, Renato Puppi Munhoz*, Egberto Reis Barbosa**

Professor Jean-Martin Charcot (Charcot), the brilliant French neurologist considered the father of modern neurology and the first professor of diseases of the nervous system, is regarded as one of the most important researchers in the field of clinical neurology in the $19^{\text {th }}$ century (Figure 1). ${ }^{1-3}$

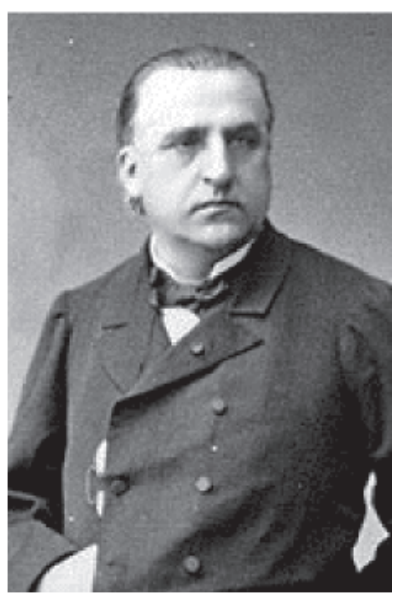

Figure 1 - J-M Charcot (1825-1893) (Extracted from http:// webperso.easyconnect.frlbaillment/images/charcot.gif).

Using his famous anatomo-clinical method, Charcot described a range of neurological diseases, some of which bear his name.

Charcot's masterly contributions to neurology are exceedingly well-known, particularly those related to multiple sclerosis (or sclerosis in plaques according to Charcot's original definition), lateral amyotrophic sclerosis (or Char-

\footnotetext{
* Neurology Department, Federal University of Paraná Medical School. ** Division of Neurology, University Medical School- São Paulo/SP,Brazil. Email: egbertob@8415.com.br
}

cot's disease), Charcot-Marie-Tooth disease (or hereditary motor and sensory neuropathy, according to the current definition), motor ataxia, Parkinson's disease, and Gilles de la Tourette syndrome, among other diseases. ${ }^{1-8}$

Charcot's contributions in different areas of internal medicine have been reviewed by several authors over the past few years. ${ }^{9-15}$

However, other important contributions by Charcot are little remembered today, and this led us to undertake this short review of these contributions in different areas of internal medicine as well as in pathological anatomy, neurology, and psychiatry.

\section{Little-Known Scientific Contributions of Charcot in Neurology and Psychiatry:}

Some of the countless important contributions Charcot made in the field of neurology are little known and not widely published, possibly eclipsed by the magnitude of his other world-famous contributions. Along with his pupil, the pathologist Charles Joseph Bouchard, Charcot described the Charcot-Bouchard microaneurysms, still recognized as one of the main causes of primary intracerebral hemorrhages. Some of the little-known diseases described by Charcot include the disease known as Charcot's ophthalmoplegic migraine (paralysis of the Oculomotor Nerve in patients with classic migraine $)^{16,17}$; Charcot-Joffroy syndrome, a rare form of cervical myelopathy known as idiopathic hypertrophic cervical pachymeningitis; and ErbCharcot paralysis (spinal syphilis with sensory deficits, spastic paresis, and amyotrophy). He published a number of papers related to aphasia (he created a diagram of the sinus in which he explained the circuits involved in the speech process $)^{1}$ and visual agnosia ${ }^{1,7,12,13}$ among other contributions. There are several other diseases described by 
Charcot and his colleagues, such as Charcot-Wilbrand syndrome and Souques-Charcot syndrome. ${ }^{12}$

Charcot's first studies regarding to decubitus ulcers are particularly noteworthy, because they are very common in bedridden patients suffering from neurological lesions. He believed that decubitus ulcers were caused by the loss of neurotrophic factors and suggested that their appearance could be a sign of bad prognosis, indicating that the patient would soon die. He called these lesions "decubitus ominosus." ${ }^{18,19}$ He also stated that decubitus ulcers would rarely be found, or would be absent, in amyotrophic lateral sclerosis. ${ }^{7,19,20}$

According to current medical terminology, in the last phase of his brilliant career, Charcot would be considered a psychiatrist. ${ }^{21-23}$ His contributions to this field are very relevant, particularly those related to hysteria. His work in this area, including his studies of hypnosis, made him world famous, and his Salpêtrière Neurological Service took the lead in the field. ${ }^{1}$

His studies of the diseases known as somatoform disorders and his attempts to better catalog them and bring them out of the scientific obscurity which surrounded them at the time were remarkable. Another of Charcot's contributions in the intersection with psychiatry was related to studies into obsessive-compulsive disorder (which he called "idée fixe"), particularly in patients with tics or Tourette's syndrome. ${ }^{1-3,21-23}$

\section{Little-Known Scientific Contributions of Charcot in Internal Medicine:}

Charcot's scientific contributions in different areas of internal medicine, and subsequently in neurology, reflect the renowned researcher's increasing involvement in clinical medicine in his earlier years, more specifically in neurology following the creation of the chair in Diseases of the Nervous System in 1883 in the Faculty of Medicine at the University of Paris. ${ }^{1-3,7}$

His inaugural thesis, defended at the Faculty of Medicine at the University of Paris in 1853, was a classical description of progressive chronic rheumatism, differentiating it from cases of gout. ${ }^{3}$ The title of Charcot's thesis was "Étude pour servir à l'histoire de l'affection décrite sous le nom de goute asthénique primitive, nodosités des jointures, rhumatisme articulaire chronique (forme primitive)."3

In 1863, with his student Cornil, Charcot studied anatomical lesions of the joints and kidneys in patients diagnosed with gout and investigated the possibility of a connection with lead poisoning. ${ }^{3}$ Even without having established a correlation with uric acid levels, Charcot investigated the effectiveness of colchicine in the treatment of gout. ${ }^{1,8}$
The lesion known as Charcot's joint, which was actually an arthropathy described in patients with tabes dorsalis (neurosyphilis) or progressive motor ataxia, began to be defined as a result of studies that Charcot started in 1868 , and the disease became known worldwide as an arthropathy associated with motor ataxia during the $7^{\text {th }}$ International Medical Congress held in London in $1881 .^{3}$ In 1883, Charcot and Fere published a study about the tabetic foot ("Pied Tabétique"). ${ }^{3}$

Another articular disease described by Charcot is related to the well-known diabetic foot disease. Many patients with diabetic foot actually present an arthropathy known as Charcot's arthropathy, which is a progressive degenerative arthropathy associated with various kinds of neuropathic diseases but which is undoubtedly much more common in patients with diabetes mellitus, ${ }^{9}$ as determined by Jordan as late as $1936 .{ }^{10}$ This arthropathy predominantly affects the feet, leading to structural deformities and the risk of developing ulcers on the feet and even osteomyelitis. This clinical picture has become known world wide as diabetic Charcot's foot. ${ }^{9-11}$

Charcot also studied exophthalmic goiter, a disease previously described by Basedow in Germany and Granes in England. ${ }^{3}$ He described an improvement in the clinical findings in pregnant patients and also described the presence of different sorts of tremors in the disease, inspiring his coworker Pierre Marie to write a thesis on Basedow's disease. ${ }^{3}$

Another of Charcot's contributions, previously studied by Von Zencker in 1851, was to define the crystals known as Charcot-Leyden or Charcot-Robin crystals found in patients with asthma. These crystals are actually phosphate crystals and are found in the sputum of patients with bronchial asthma and also in the feces of patients with ulcerative colitis. Similarly, Charcot-Neumann crystals, which also contain phosphate crystals were described in semen. ${ }^{12,13}$

Charcot also described what is known as the biliary triad or Charcot's triad. The triad is characterized by the presence of recurring abdominal pain in the upper right quadrant associated with fluctuating jaundice and intermittent fever with shivers and is associated with the presence of acute cholangitis caused by choledocholithiasis. ${ }^{11,14}$

Intermittent claudication of arterial origin, also known as Charcot's angina cruris, was originally described by Charcot. ${ }^{12,13}$ It is characterized by the presence of pain, discomfort, weakness, or leg cramps. These are most common after physical exercise or walks and disappear after rest. The disorder is the result of arterial obstruction of the terminal aorta and iliac arteries, causing reduced circulation in the leg muscles. ${ }^{12}$ Charcot described this disease in detail in a soldier who had been injured by a firearm and who developed an aneurysm that formed a thrombus blocking the iliac arteries. He based his study on the description, 
published in an article in 1831 by the Parisian veterinary surgeon, Jean-François Bouley, of claudication in a horse that pulled a carriage through the streets of Paris and had difficulty using its hind feet whenever it had to exercise more stenuously. The animal presented thrombi obstructing the femoral arteries. ${ }^{12,15,24,25}$ Another contribution related to the field is Charcot's edema, a painful and bluish edema described in women with hysterical paralysis. ${ }^{1,7}$

In the field of medicine known today as neurocardiology, Charcot gave a detailed description of vasovagal syncope, which is characterized by transitory attacks of significantly reduced heartbeat, reduced arterial pressure, and loss of consciousness. ${ }^{12,13} \mathrm{He}$ also described the type of syncope triggered by coughing (called Charcot's vertigo or cough syncope, in which the fit of coughing provokes a spasm of the glottis followed by vertigo and then syncope) as well as syncope triggered by compression of the carotid sinus (carotid sinus hypersensitivity syndrome). In the latter condition, initially described by J.N. Czermak in 1866 and also known as the Charcot-Weiss-Baker syndrome, the attacks of syncope, which are transitory and associated with bradycardia and arterial hypotension, are related to the application of pressure on the neck at the location of the fork in the common carotid artery, or even to sudden rotation of the neck or the use of a tight collar. ${ }^{12,13}$

Charcot can also be considered to have pioneered the study of diseases of the elderly, although his contributions in the fields of geriatrics and gerontology are not well known. ${ }^{26,27} \mathrm{He}$ was one of the pioneers in setting up rehabilitation clinics with physiotherapy, speech therapy, hydrotherapy, and electrical stimulation of paralyzed muscles, and he also recommended treatment with electrostatic baths supplemented with sulfur salts in thermal springs or spas. ${ }^{1,8}$

Lastly, one cannot forget that Charcot described a large number of diseases in different areas of internal medicine including neurology and psychiatry, causing Lellouch to define him as the "discoverer of diseases." ${ }^{28}$ Charcot made use of the well-known anatomo-clinical method and thus also became recognized as an important anatomo-pathologist. $^{29}$

\section{ACKNOWLEDGMENTS}

The authors thank Professor Osvaldo M. Takayanagui (FMRP-USP) and Doctor Tarso Adoni (HC-FMUSP), for their collaboration.

\section{REFERENCES}

1. Goetz CG, Bonduelle M, Gelfand T. Charcot. Constructing neurology. New York: Oxford University Press; 1995.

2. Goetz CG. Charcot. The Clinician. The Tuesday lessons. New York: Raven Press; 1987.
3. Guillain G. J-M Charcot. 1825-1893. His life - his work. Paul B. Hoeber, editor. New York: INC; 1959.

4. Teive HAG. Charcot's contribution to Parkinson's disease. Arq Neuropsiquiatr 1998;56;141-5. 
5. Teive HAG, Zavala JA, Iwamoto FM, Sa D, Carraro H Jr, Werneck LC. Contributions of Charcot and Marsden to the development of movement disorders in the 19th and 20th centuries. Arq Neuropsiquiatr 2001;59:633-6.

6. Teive HAG, Almeida SM, Arruda WO, Sá DS, Werneck LC. Charcot and Brazil. Arq Neuropsiquiatr 2001;59:295-9.

7. Sigerson G. Lectures on the diseases of the nervous system by J-M Charcot. Hafner Publishing Company, New York, 1962.

8. Goetz CG, Bonduelle M. Charcot as therapeutic interventionist and treating neurologist. Neurology 1995;45:2102-6.

9. Lee L, Blume PA, Sumpio B. Charcot joint disease in diabetes mellitus. Ann Vasc Surg 2003;17:571-80.

10. Sanders LJ. The Charcot foot: historical perspective 1827-2003. Diabetes Metab Res Rev. 2004; Suppl 1: S4-S8.

11. Slater RA, Ramos Y, Buchs A, Rapoport MJ. The diabetic Charcot foot. Isr Med Assoc J 2004;6:280-3.

12. Kundu AKR. Charcot in Medical Eponyms. JAPI 2004;.53:716-8.

13. www.whonamedit.com/doctor.cfm/19.html (2002). Jean-Martin Charcot.

14. Lipsett PA, Pitt HA. Acute cholangitis. Surg Clin North Am. 1990;70:1297-312.

15. Lacombe M. The history of intermittent claudication due to arterial disease. Ann Chir 2005;130:440-4.

16. Pollola E, Israel A, Gersellas AC. On an atypical case of recurrent paralysis of the oculomotor nerve (Charcot's ophthalmoplegic migraine). Arq Bras Oftalmol 1966;29:101-4.
17. Lapresle J, Desi M. Painful ophthalmoplegia. Acta Neurol Belg 1977;77:331-50.

18. Levine JM. Historical perspective on pressure ulcers: The decubitous ominosus of Jean-Martin Charcot. J Am Geriatr Soc. 2005;53:124851.

19. Levine JM. Historical perspective: the neurotrophic theory of skin ulceration. J Am Geriatr Soc 1992;40:1281-3.

20. Ono S. The skin in amyotrophic lateral sclerosis. Amyotroph Lateral Scler Other Motor Neuron Disord. 2000;1:191-9.

21. White MB. Jean-Martin Charcot's contributions to the interface between neurology and psychiatry. Can J Neurol Sci. 1997;24:254-60.

22. Lellouch A. Charcot's epistemological concept. Hist Sci Med. 1994;28:297-305.

23. Widlocher D, Dantchev N. Charcot and hysteria. Rev Neurol (Paris). 1994;150:490-7.

24. Sugar O. Jean-Francois Bouley (Bouley jeune). Pioneer investigator in intermittent claudication. Spine. 1994;19:346-9.

25. Bollinger A, Eckert J, Ruttimannn B, Becker F. The "galloping" history of intermittent claudication. Vasa. 2000;29:295-9.

26. Lellouch A. J. M Charcot: also, pioneer of geriatrics. Rev Prat. 1966;46:15-8

27. Huard P. J.M. Charcot's gerontology. Rev Neurol (Paris). 1982;138:98995.

28. Lellouch A. Charcot, discoverer of diseases. Rev Neurol (Paris). 1994;150:506-10.

29. Bonduelle M. Charcot, anatomo-pathologist. Arch Anat Cytol Pathol. 1994;42:171-80. 